\title{
Hypomethylation of the aquatic invasive plant, Ludwigia grandiflora subsp hexapetala mimics the adaptive transition into the terrestrial morphotype
}

Julien Genitoni ${ }^{1,2}$, Danièle Vassaux ${ }^{1}$, Alain Delaunay ${ }^{2}$, Sylvie Citerne ${ }^{3}$, Luis Portillo ${ }^{1}$, Marie-Pierre Etienne $^{4}$, David Renault ${ }^{5,6}$, Solenn Stoeckel ${ }^{7}$, Dominique Barloy ${ }^{1, *}$, Stéphane Maury ${ }^{2}$

${ }^{\mathbf{1}}$ ESE, Ecology and Ecosystem Health, Institut Agro, INRAE, 35042, Rennes, France

${ }^{2}$ Laboratoire de Biologie des Ligneux et des Grandes Cultures (LBLGC), EA1207 USC1328 INRA, Université d’Orléans, 45067, Orléans, France

${ }^{3}$ Institut Jean-Pierre Bourgin, INRAE, AgroParisTech, Université Paris-Saclay, 78000, Versailles, France

${ }^{4}$ Institut Agro, CNRS, Université Rennes, IRMAR [(Institut de Recherche Mathématique de Rennes)] -UMR 6625, F-35000 Rennes, France

${ }^{5}$ UMR CNRS 6553 EcoBio, University of Rennes 1, Rennes, France

${ }^{6}$ Institut Universitaire de France, 1 rue Descartes, Paris, France

${ }^{7}$ IGEPP, INRAE, Institut Agro, Université Rennes, 35653, Le Rheu, France

\section{Correspondence}

*Corresponding author,

e-mail: dominique.barloy@agrocampus-ouest.fr

Ongoing global changes affect ecosystems and open up new opportunities for biological invasion. The ability of invasive species to rapidly adapt to new environments represents a relevant model for studying short-term adaptation mechanisms. The aquatic invasive plant, Ludwigia grandiflora subsp hexapetala, is classified as harmful in European rivers. In French wet meadows, this species has shown a rapid transition from aquatic to terrestrial environments with emergence of two distinct morphotypes in five years. To understand the heritable mechanisms involved in adjustment to such a new environment, we investigate both genetic and epigenetic as possible sources of flexibility involved in this fast terrestrial transition. We found a low overall genetic differentiation between the two morphotypes arguing against the possibility that terrestrial morphotype emerged from a new adaptive genetic capacity. Artificial hypomethylation was induced on both morphotypes to assess the 
epigenetic hypothesis. We analysed global DNA methylation, morphological changes, phytohormones and metabolite profiles of both morphotype responses in both aquatic and terrestrial conditions in shoot and root tissues. Hypomethylation significantly affected morphological variables, phytohormone levels and the amount of some metabolites. The effects of hypomethylation depended on morphotypes, conditions, and plant tissues, which highlighted differences among the morphotypes and their plasticity. Using a correlative integrative approach, we showed that hypomethylation of the aquatic morphotype mimicked the characteristics of the terrestrial morphotype. Our data suggest that DNA methylation rather than a new adaptive genetic capacity is playing a key role in L. grandiflora subsp hexapetala plasticity during its rapid aquatic to terrestrial transition.

Abbreviations - ABA, abscissic acid; Am, aquatic morphotype; Ctrl, control; DMS, dry mass of shoots; DMR, dry mass of roots; FMS, fresh mass of shoots; FMR, fresh mass of roots; IAA, auxin; JA, jasmonic acid; JL, leucine jasmonyl acid; LI, length of internodes; LP, length of plant; nbB, number of nodes with buds; nbL, number of leaves; nbI, number of internodes; nbNR, number of nodes with roots; Rr, root ratio (FMR/DMR); SA, salicylic acid; Sr, shoot ratio (FMS/DMS); Tm, terrestrial morphotype; WC, water content ((FMS+FMR)/(DMS+DMR)); Zeb, zebularine.

\section{Introduction}

Global changes and human activity impact ecosystems and increase opportunities of geographic expansion of invasive species (van Kleunen et al. 2015, Early et al. 2016), thus increasing the cascading economic and ecological consequences (Theoharides and Dukes 2007). However, the capabilities of organisms to adapt rapidly to newly encountered environmental conditions are crucial for the establishment of a viable population, especially for plants that are sessile organisms. Moreover, invasion phenomenon can occasionally result in founder effects, i.e., a large decrease in the genetic diversity of the few establishing propagules. Phenotypic plasticity, which is the ability of one genotype to produce several phenotypes depending on the environment (Pigliucci 2005), is commonly cited as an important factor favouring the invasion success. Theoretically, organisms characterized by a greater plasticity should be able to thrive in a larger range of environmental conditions compared to their less-plastic relatives. Yet, the high level of phenotypic plasticity reported in some invasive species (Trussell and Smith 2000, Sexton et al. 2002, Daehler 2003, Davidson et al. 2011, Morris 2014) is still questioned (Chown et al. 2007, Godoy et al. 2011, Matzek, 2012, Lamarque et al. 2013), 
and the underpinning mechanisms at the basis of this flexibility, including epigenetics, remain to be established.

Epigenetics can be defined as any non-genetic molecular modification of the genome that alters gene expression and that can be heritable (Meyer 2018). This definition broadly encompasses several levels of chromatin modifications, including DNA methylation, histone modifications and variants, and non-coding RNAs (Duncan et al. 2014, Allis and Jenuwein 2016). It has recently been suggested that epigenetics is a potential source of flexibility involved in the success of invasive species, allowing organisms to express advantageous phenotypes across a broader range of environments (Richards 2006, Richards et al. 2017, for a recent review see Marin et al. 2019).

DNA methylation is the most studied epigenetic marker; it consists of the addition of a methyl group to DNA cytosines. This addition is provided de novo and maintained by methyltransferase enzymes through three different sequence contexts in plants: CG, CHG and CHH (Meyer 2015). Over recent years, many studies have highlighted the role of DNA methylation in many biological and ecological mechanisms in plants, such as development (Guo et al. 2018, Li et al. 2018), responses to biotic and abiotic stressors (Tricker 2015, Crisp et al. 2016, Lämke and Bäurle, 2017), cellular-stress response memory and priming (Mauch-Mani et al. 2017, Le Gac et al. 2018, Sow et al. 2018, Le Gac et al. 2019), phenotypic plasticity (Gourcilleau et al. 2010, Baulcombe and Dean 2014, Kooke et al. 2015, Conde et al. 2017, Lafon-Placette et al. 2018, Maury et al. 2019), and possibly adaptation (Bräutigam et al. 2013, Kawakatsu et al. 2016, Rey et al. 2016, Schmid et al. 2018, Gourcilleau et al. 2019). Kooke et al. (2015) used 99 Epigenetic Recombinant Inbred Lines (epiRILs) of Arabidopsis thaliana, consisting of crosses between the parents Col-0 and the hypomethylated mutant lines $d d m 1$ and $d d m 2$, to compare the morphological responses of the plants exposed to saline conditions. These authors reported the existence of several distinct phenotypes among epiRILs and discovered that hypomethylation affects phenotypic plasticity during stress response.

Ludwigia grandiflora subsp hexapetala (Nesom \& Kartesz 2000), the water primrose native to South America, is an aquatic invasive plant in Europe (Hussner et al. 2016), which can colonize a wide range of habitats (Haury et al. 2014). In France, this plant invades aquatic habitats, such as static or slow-flowing waters, riverbanks, and has more recently been reported thriving in wet meadows (Dandelot et al. 2005, Lambert et al. 2010). As mentioned in Billet et al. (2018), L. grandiflora subsp hexapetala, is an amphibious plant characterized by two distinct morphotypes: one being aquatic (Am), while the second one being terrestrial (Tm, wet meadows). In addition to raising ecological questions, the secondary colonization of wet meadows could lead to a loss of financial support for 
farmers because of depreciation in fodder value and abandonment of pasturing. In its original condition, aquatic plants are characterized by an elongated morphology with a low leaf number. Conversely, terrestrial plants present a bushy morphology with a greater root system and more leaves than the aquatic morphotype (Haury et al. 2014, Billet et al. 2018). In addition, Billet et al. (2018) identified an accumulation of metabolites in roots characterising the plants thriving in the terrestrial condition, associated with the regulation of the following pathways: amino sugar and nucleotide sugar metabolism, starch and sucrose metabolism, as well as galactose, fructose, and mannose metabolism. Two metabolic pathways for shoots in the aquatic condition were identified: the valine, leucine, and isoleucine metabolism and degradation pathways.

Water primrose reproduces essentially by clonal propagation, and each population is thus expected to exhibit a low genetic diversity, as demonstrated in Fallopia spp (Holm et al. 2017). According to Zhang et al. (2013), this kind of organisms make them good candidates for testing the role of epigenetic mechanisms in invasive plants. Thus, the aim of this study is to explore the involvement of genetic and epigenetic components in the adaptation of L. grandiflora subsp hexapetala to the terrestrial environment. We first examined the genetic differentiation of the aquatic and terrestrial morphotypes using SNPs and their epigenetic differentiation using global DNA methylation assessed by classical HPLC techniques (Lambé et al. 1997, Trap-Gentil et al. 2011, Teyssier et al. 2014, Alonso et al. 2016, Kurdyukov and Bullock 2016, Yong et al. 2016, Sow et al. 2018). Indeed, global DNA methylation (\%mC) has been widely used in plants to obtain useful information on DNA methylation (Causevic et al. 2006, Gourcilleau et al. 2010, Trap-Gentil et al. 2011, Teyssier et al. 2014, Alonso et al. 2015, Alonso et al. 2016, Le Gac et al. 2018, Sow et al. 2018, Gourcilleau et al. 2019).

In a second part of the work, we explored whether DNA methylation is differently mobilized by terrestrial and aquatic morphotypes according to the environment, therefore possibly participating to the fast transition from aquatic to terrestrial life of the water primrose, as suggested for the amphibious plant, Alternanthera philoxeroides in response to change of water availability (Li et al. 2013). Here, we used a pharmacological approach using zebularine to perturb DNA methylation in aquatic and terrestrial morphotypes from the same populations of L. grandiflora subsp hexapetala previously used by Billet et al. (2018). To characterize the hypomethylation effect of zebularine, a correlative approach and integrative analysis were conducted using morphological, physiological (metabolomics and phytohormones) and methylation percentage variables. 


\section{Material and methods}

\section{Plant material and experimental design}

Aquatic (Am) and terrestrial (Tm) morphotypes of L grandiflora subsp hexapetala grew as single dense continuous sympatric population in Mazerolles swamps (Nantes, France, N47 23.260, W1 28.206), separated at fine spatial scale in two subpopulations with different environments, respectively flooded the year round or ground-emerged a part of the year (as sympatric populations). Aquatic and terrestrial morphotypes were sampled from five collection points $(50 \mathrm{~cm} * 50 \mathrm{~cm}$ frame), 10 metres apart, giving a total of 10 collection points. After collection, plants were grown in a greenhouse in aquatic conditions for Am and terrestrial conditions for Tm, as described in Billet et al. (2018).

For the zebularine experiment, a 10-cm portion from the stem apex was collected, without roots, buds, and lateral stems. All plants were preconditioned for 2 weeks, as described in Billet et al. (2018), to promote root development. For morphological analyses, two biological replicates of nine plants were randomly grouped by three plants per container for aquatic (Am-a and Tm-a) and terrestrial (Am-t and Tm-t) conditions for both morphotypes, as described in Billet et al. (2018). The plants were then placed in a growth chamber $\left(22^{\circ} \mathrm{C}, 16 \mathrm{~h}\right.$ day/ $8 \mathrm{~h}$ night). Similarly, three biological replicates of six plants were carried out for physiological (phytohormone and metabolite quantifications) and \%mC analyses for each morphotype (Am and Tm), condition (-a and $-\mathrm{t})$, and treatment (ctrl and zeb) combination, for a total of 288 plants. Zebularine (Sigma-Aldrich) treatment at $150 \mu \mathrm{M}$ was applied in a liquid solution at the beginning of the experiment and renewed 7 days later. Plants without zebularine were grown as a control. Sampling for physiological and methylation analyses was conducted 14 days after the beginning of the experiment. De novo shoots and roots, taken $5 \mathrm{~cm}$ from the apex (including stems, leaves, and buds) were sampled separately from six randomly collected plants per morphotype (Am or Tm), treatment (zebularine or control) and condition (aquatic or terrestrial). Samples for physiological analysis were pooled and immediately snap-frozen in liquid nitrogen, then lyophilized over $48 \mathrm{~h}$ using a Cosmos 20K (Cryotec) and stored at $-80^{\circ} \mathrm{C}$.

\section{Genetic differentiation}

To assess the degree of genetic differentiation between the two sub-populations, we genotyped 15 individuals per group/morphotype at 38 SNP loci randomly sampled on the genome. Considering our sample size, we computed unbiased $\mathrm{F}_{\mathrm{ST}}$ values at each locus as recommended by Hardy (2016) with 
the estimated average number of pairwise differences between two individuals sampled from the total population or within sub-populations (aquatic or terrestrial morphotypes).

\section{Graph of genetic distances between phenotypes}

To assess the homogeneity of the genetic background between terrestrial and aquatic individuals, we computed the allele sharing distances (ASD) between pairs of individuals within subpopulations and between subpopulations. ASD is a common metric well adapted to SNPs that measures the identityby-state and relatedness between individuals (Stevens et al. 2011). ASD measures the probability of allele divergence between pairs of individuals across loci and is computed as the probability with which two SNP alleles, one drawn randomly from each of the two individuals, differ in state. Ranging from zero to one, low values of ASD mean that individuals are tightly related with identical genomes while high values of ASD mean less genetic relatedness and older common ancestrality. For example, the ASD value between native Americans (Pima) from a same group is $0.6 \pm 0.05$ and $0.75 \pm 0.05$ between European coming from a same country (Mountain and Ramakrishnan 2005).

Genetic graphs are simple and common construction of more complex systems composed of nodes (here individuals) related by edges (here ASD values) to visualize the degree of ancestrality and admixture between individuals in population with different phenotypes and ecology (Rozenfeld et al. 2008, Gao and Martin 2009, Dyer 2015). Two adjacent individuals (nodes) linked by an edge are the most identical-by-state, thus the most genetically-related in the considered sample. Genetic distance between pairs of distant individuals corresponds to the sum of all the edges to walk through between their nodes. The smaller the value between pairs of individuals, the more identical-by-state and closer related they are. If terrestrial phenotypes are supported by a hereditary genetic feature inherited from a single ancestral mutation and recombination event(s), we expect a clear separation (long edges, gap) between nodes, with higher magnitude of genetic distances between terrestrials and aquatics than within terrestrials.

\section{Morphological analyses}

Nine plants per morphotype, condition and treatment were analysed. The following morphological, growth and fitness traits were measured:

Length of the plant (LP) in centimeters (cm), number of internodes (nbI), and number of leaves (nbL), were recorded in order to characterize plant morphology. The length of the internodes in centimeters was calculated as the ratio of LP/nbI. Number of nodes with roots (nbNR) and number of 
nodes with buds (nbB) variables are associated with the fitness of the plant. As mentioned in Billet et al. (2018) fitness of L. grandiflora subsp hexapetala is considered as the ability to produce propagules from buds or nodes with roots. L. grandiflora subsp hexapetala has the ability to form a new plant from small ( $>1 \mathrm{~cm}$ ) plant fragments. Biomass of plants in grams (g) was determined by measuring the fresh mass of shoots (FMS) and roots (FMR). After oven drying the samples at $105^{\circ} \mathrm{C}$ for $48 \mathrm{~h}$, we obtained their respective dry mass (DMS and DMR). To determine water content, the ratios of fresh/dry mass of shoots ( $\mathrm{Sr}$ ) and roots (Rr) were calculated.

\section{DNA extraction and determination of global DNA methylation percentage by HPLC}

Genomic DNA extraction was carried out using the CTAB protocol described in Lafon-Placette et al. (2013). Quantity and quality of gDNA were checked using the NanoDrop spectrometer and electrophoresis on agarose gel and ethidium bromide staining under UV light. Genomic DNA was hydrolyzed into nucleosides and analyzed by HPLC using a GeminiTM column $(150 \times 4.6$ mm, $5 \mu \mathrm{m}$; Phenomenex). Finally, an isocratic mobile phase consisting of $0.5 \%$ methanol (v/v) and $5 \mathrm{mM}$ acetic acid in water, as described by Zhu et al. (2013) and Le Gac et al. (2018) was used. Global DNA methylcytosine percentage $(\% \mathrm{mC})$ was calculated as follows:

$\% \mathrm{mC}=(\mathrm{mC} /(\mathrm{C}+\mathrm{mC})) \times 100$, where $\mathrm{C}$ is the $2^{\prime}$-deoxycytidine content and $\mathrm{mC}$ is the 5-methyl$2^{\prime}$-deoxycytidine content. For each set of conditions, we analyzed three biological replicates for each morphotype, condition and treatment. Each sample was hydrolyzed twice and two HPLC runs were carried out by hydrolysis. Controls for this procedure included the use of co-migration with commercial standards (Sigma-Aldrich), confirmation by enzyme restriction analysis, and tests for RNA contamination were based on the HPLC detection of ribonucleosides which have already been detailed in Zhu et al. (2013).

\section{Phytohormone quantification}

Quantifications of abscisic acid (ABA), salicylic acid (SA), jasmonic acid (JA), jasmonyl Leucine acid (JLA) and auxins (IAA) were carried out in both shoots and roots. For each sample, $1 \mathrm{mg}$ of dry powder was extracted with $0.8 \mathrm{ml}$ of acetone/water/acetic acid (80/19/1 v:v:v). Stable labeled isotopes of phytohormones used as internal standards were prepared as described in Roux et al. (2014). An amount of $1 \mathrm{ng}$ of each standard was added to the sample. The extract was vigorously shaken for 1 min, sonicated for $1 \mathrm{~min}$ at $25 \mathrm{~Hz}$, shaken for $10 \mathrm{~min}$ at $10^{\circ} \mathrm{C}$ in a Thermomixer (Eppendorf®) and then centrifuged $\left(8000 \mathrm{~g}, 10^{\circ} \mathrm{C}, 10 \mathrm{~min}\right.$.). The supernatants were collected, and the pellets were re- 
extracted twice with $0.4 \mathrm{ml}$ of the same extraction solution, then vigorously shaken $(1 \mathrm{~min})$ and sonicated ( $1 \mathrm{~min} ; 25 \mathrm{~Hz}$ ). After the centrifugations, the three supernatants were pooled and dried (final volume $1.6 \mathrm{ml})$.

Each dry extract was dissolved into $100 \mu \mathrm{l}$ of acetonitrile/water (50/50 v/v), filtered, and analyzed using a Waters Acquity ultra performance liquid chromatography coupled to a Waters Xevo Triple quadrupole mass spectrometer TQS (UPLC-ESI-MS/MS). The compounds were separated on a reverse-phase column (Uptisphere C18 UP3HDO, 100*2.1 mm*3 $\mu \mathrm{m}$ particle size; Interchim) using a flow rate of $0.4 \mathrm{ml} \mathrm{min}^{-1}$ and a binary gradient: (A) acetic acid $0.1 \%$ in water (v/v) and (B) acetonitrile with $0.1 \%$ acetic acid, the column temperature was $40^{\circ} \mathrm{C}$. For abscisic acid, salicylic acid, jasmonic acid, and indole-3-acetic acid we used the following binary gradient (time, \% A): (0 min, 98\%), (3 min, 70\%), (7.5 min, 50\%), (8.5 min, 5\%), (9.6 min, 0\%), (13.2 min, 98\%), (15.7 min, 98\%). Mass spectrometry was conducted in electrospray and Multiple Reaction Monitoring scanning mode (MRM mode), in positive ion mode for the indole-3-acetic acid and in negative ion mode for the other hormones. Relevant instrumental parameters were set as follows: capillary $1.5 \mathrm{kV}$ (negative mode), source block and desolvation gas temperatures 130 and $500^{\circ} \mathrm{C}$, respectively. Nitrogen was used to assist the cone and desolvation (150 $\mathrm{l} \mathrm{h}^{-1}$ and $800 \mathrm{l} \mathrm{h}^{-1}$, respectively), argon was used as the collision gas at a flow of $0.18 \mathrm{ml} \mathrm{min}^{-1}$.

\section{Metabolomic fingerprint}

Gas chromatography coupled with mass spectrometry (GC-MS) was used to scan for the metabolites that could be detected from the plant samples (amino acids, organic acids, polyamines, polyols, or sugars). For the preparation of the samples, the method described in Serra et al. (2013) was used and adapted as in Billet et al. (2018). Briefly, for each sample, an aliquot of $10 \mathrm{mg}$ of lyophilized powder was homogenized in $600 \mu \mathrm{l}$ of a solution of ice-cold methanol/chloroform (2:1, v/v). Then, a volume of $400 \mu \mathrm{l}$ of ultra-pure water was added. Samples were homogenized and centrifuged for $10 \mathrm{~min}$ at $4000 \mathrm{~g}\left(4^{\circ} \mathrm{C}\right)$. The upper phase $(128 \mu \mathrm{l})$ containing metabolites was transferred to new glass vials for roots and shoots respectively. The derivatization of the samples was conducted with a CTC CombiPAL autosampler (CTC Analytics AG), as described in Serra et al. (2013). The GC-MS platform consisted of an Agilent 7890B gas chromatograph coupled to a 5977B mass spectrometer. The injector was held at $250^{\circ} \mathrm{C}$, and the temperature of the oven ranged from 70 to $170^{\circ} \mathrm{C}$ at $5^{\circ} \mathrm{C}$ per min, from 170 to $280^{\circ} \mathrm{C}$ at $7^{\circ} \mathrm{C}$ per min, and from 280 to $320^{\circ} \mathrm{C}$ at $15^{\circ} \mathrm{C}$ per min; at the end of the temperature ramps, the oven remained at $320^{\circ} \mathrm{C}$ for $4 \mathrm{~min}$. A $30 \mathrm{~m}$ fused silica column (HP5 MS 30 
m, I.D. 0.25 mm, thickness 0.25 $\mu \mathrm{m}$, 5\% Diphenyl / 95\% Dimethylpolysiloxan, Agilent Technologies) was used, with helium as the gas carrier at $1 \mathrm{ml}$ per min. The temperatures of the transfer line and ion source were 280 and $230^{\circ} \mathrm{C}$, respectively. The split mode (split ratio: 2:1) was used for the injection of $1 \mu \mathrm{l}$ of each sample, and detection was realized by electronic impact (electron energy: $70 \mathrm{eV}$ ), in full scan mode. The detected peaks were annotated with MassHunter. Most detected metabolites were identified, and calibration curves were drawn for calculating the concentration of each metabolite.

\section{Phenotypic plasticity}

The phenotypic plasticity of the plants exposed to the different experimental conditions was calculated by using morphological and phytohormone variables and computing a "Relative distance plasticity index” RDPI, as suggested by Valladares et al. (2006). RDPI $\left.=\sum\left(\mathrm{dij} \rightarrow \mathrm{i}^{\prime} \mathrm{j}^{\prime} /\left(\mathrm{xi}^{\prime} \mathrm{j}{ }^{\prime}+\mathrm{xij}\right)\right) / \mathrm{n}\right)$, where $\mathrm{n}$ is the total number of distances, and $\mathrm{j}$ and $\mathrm{j}$ ' are two individuals belonging to different treatments ( $\mathrm{i}$ and I'). This index ranges from 0 (no plasticity) to 1 (maximal plasticity). The different RDPIs were calculated for morphological and phytohormone data by comparison of aquatic and terrestrial morphotype values in aquatic versus terrestrial conditions and treated and not treated with zebularine.

\section{Statistical analysis}

The effects of the zebularine treatment on the morphology and physiology of both water primrose morphotypes were assessed by running analyses of variance (ANOVAs) and principal component analyses (PCAs; FactomineR package).

Four-way ANOVAs were carried out with morphotype, treatment, condition and biological replicates as factors. Biological replicate and triple interaction effects are mainly not significant for all data. The effect of each factor is quantified by both type I and type II variance decomposition. As no difference between type I and type II have been observed, only ANOVA results of type I are presented in the text and tables of the article. Two and three-way interactions were then analyzed. The normality of residuals and the homoscedasticity were verified by Shapiro-Wilk's and Bartlett's tests, and normality was achieved, when required, by transforming morphological traits and the metabolite concentrations (Log10). Within the four ways analysis of variance models, the difference between groups have been examined through the comparisons of adjusted means thanks to the emmean package (Russell Lenth, 2018) of the R software (Core Team, 2018). The Tukey's test was used to conclude. 
We also made two PCA incorporating morphological traits, phytohormones and a subset of six metabolites which are correlated with methylation percentage and some other metabolites significantly affected by hypomethylation according to the ANOVA. Then for the first PCA, we calculated the distances between the barycentres of the 8 PCA groups and also made a hierarchical classification (HCPC) with FactomineR packages.

To link metabolites analysis to metabolic pathways, we performed pathway enrichment analyses in Metaboanalyst 3.0 (Xia et al. 2015). Fisher's exact test algorithm was performed for these pathway analyses with Arabidopsis thaliana as the reference model. In this procedure, the number of hits between the metabolites in our dataset and all metabolites of a given pathway was calculated. Data presented in the figures are untransformed.

\section{Results}

Genetic differentiation between aquatic and terrestrial morphotypes of the invasive $L$. grandiflora subsp hexapetala plant

Aquatic and terrestrial morphotypes showed low genetic differentiation with a median $\mathrm{F}_{\mathrm{ST}}$ of 0.019 . All the genotyped alleles were shared by the two subpopulations. Over the 38 genotyped SNPs, 27 loci showed no genetic differentiation between aquatic and terrestrial subpopulations (FST values under 0.05; Hartl and Clark 1997, Frankham et al. 2010). Only two SNPs showed high $F_{\text {ST }}$ values (0.488 and 0.527) but those two values were due to skewed allele frequencies in a commonly-shared allele pool rather than due to privative alleles or a narrow restricted ancestrality (Fig. 1). Genetic divergences (ASD) between pairs of individuals from different subpopulations were on average 0.328 (95\% confidence interval: [0.315, 0.342]), on the order of values expected between sister plants sharing the same parents. ASD values within and between subpopulations were on the same order of magnitude, with no gap between subpopulations and even with intermingled individuals from different subpopulations (Fig. S1). The graph topology was nearly linear with regularly distributed individuals which was consistent with isolation-by-distance scenario (Templeton 2006). It showed some grapes of individuals diverging from only one to three alleles, which is expected under clonal reproduction (Rozenfeld et al. 2007). Altogether, the data suggested very recent common ancestors and even shared parents between individuals of different morphotypes.

\section{Artificial hypomethylation of the aquatic and terrestrial morphotypes}


A 14-day zebularine treatment was applied to induce DNA hypomethylation in Am and Tm morphotypes of the invasive L. grandiflora subsp hexapetala plant grown in aquatic and terrestrial conditions. Only de novo-formed shoots during the treatment were used to assess the global DNA methylation percentage (\%mC) using the HPLC method (Fig. 2; see Materials and Methods for procedure). The methylation percentages ranged from 25.9 to $29.8 \%$ for control plants and from 20.9 to $23.9 \%$ for plants treated with zebularine (Fig. 2). A 4-way analysis of variance was carried out by comparison of morphotype (Am or Tm), treatment (zebularine or control), condition (aquatic or terrestrial) and biological replicates. The DNA methylation percentage was significantly affected by morphotypes, treatment and the interaction between condition and treatment ( $P=8.82 \mathrm{e}-03,4.88 \mathrm{e}-08$ and 1.86e-2, respectively). ANOVA analysis revealed a significant decrease in \%mC in zebularinetreated plants $(P=4.88 \mathrm{e}-08)$. Specifically, the zebularine treatment induced a methylation decrease ranging from 7.2 and $8.6 \%$ for Am and Tm grown in terrestrial conditions, respectively, and from 4.3 and $5.1 \%$ in aquatic conditions, respectively (Fig. 2). However, we observed similar methylation levels between morphotypes independently of conditions for the two treatments.

The data showed that no significant variation in global DNA methylation was observed among morphotypes and conditions, but a significant hypomethylation was obtained after a 14-day zebularine treatment in both morphotypes and conditions.

\section{Growth, morphology and phenotypic plasticity of hypomethylated aquatic and terrestrial morphotypes}

After a 14-day treatment, Am and Tm grown in aquatic (-a) and terrestrial (-t) conditions were pictured (Fig. 3A), and morphology, biomass and water content were measured (Fig. 3B). No necrosis symptoms were observed for zebularine-treated plants (Fig. 3A). Analyses of variance were carried out and showed that morphology and growth were altered (Figs 3A,B and S2, Table S1). Hypomethylation had a significant impact on 6 of the 13 measured traits (Table S1). A significant impact was observed on hypomethylated plants, exemplified by the increased number of leaves in hypomethylated Am in aquatic conditions (Am-a; Fig. 3B). Effects of hypomethylation were also observed with the decrease in fresh mass of roots of the hypomethylated Tm in terrestrial conditions (Tm-t; Fig. 3B) Indeed, zebularine treatment impacted the two morphotypes differently when grown in their original conditions (Am-a vs Tm-t), but also when conditions were shifted (Am-t vs Tm-a; Figs 3B and S2, Table S1) with significant interaction between morphotype and treatment for some 
morphological traits. Hypomethylation also significantly decreased the water content (Fig. 3B and Table S1).

Another strong difference revealed by the analyses of variance was for the growth conditions (aquatic vs terrestrial), independently of the zebularine treatment. Plants grown in aquatic conditions showed an elongated morphology, with a greater plant length and length of internodes, and greater water content and shoot ratio (Table S1, Fig. S2). On the contrary, plants having grown in terrestrial conditions were characterized by a greater number of leaves, number of internodes, biomass variables (fresh and dry masses of roots and shoots) and number of buds (Figs 3A,B and S2, Table S1).

To compare levels of phenotypic plasticity in response to DNA hypomethylation on the different variables, a relative distance plasticity index (RDPI; Valladares et al. 2006) ranging from 0 (no plasticity) to 1 (maximal plasticity) was calculated for each trait and morphotype across treatments (Tables 1 and S2). This index gives an unbiased estimation of the levels of phenotypic variation and allows the exploration of plasticity with strong statistical power to test for differences in plasticity between genotypes. Interactions between morphotype and treatment effects were detected for most variables (Table S2). However, the two morphotypes showed significantly distinct RDPI for a majority of morphological, biomass and water content variables (Tables 1 and S2). The terrestrial morphotype exhibited higher phenotypic plasticity for biomass variables as opposed to the aquatic morphotype, which showed higher RDPI (but weak RDPI values) for water content and morphological variables. In response to DNA hypomethylation, phenotypic plasticity of 8 out of 13 variables was affected in both morphotypes (Table 1). Furthermore, phenotypic plasticity of the terrestrial morphotype was negatively affected by DNA hypomethylation, while RDPI of aquatic morphotype was positively affected for biomass and water content variables.

Altogether, results showed that growth and morphology as well as phenotypic plasticity were affected in hypomethylated morphotypes in aquatic and terrestrial conditions.

\section{Phytohormone balance in hypomethylated aquatic and terrestrial morphotypes}

Quantification of phytohormones (SA, Auxin, LJA, JA and ABA) revealed that terrestrial condition is associated with the highest amounts of all phytohormones in comparison to aquatic condition, independently of morphotype (Figs 4 and S3, Table S3). Organ distribution between shoot and root showed that SA is more present in shoot, while LJA is measured in greater amounts in root. Auxin and JA did not show strong variation among organs. 
Significant effects of hypomethylation on phytohormones were detected: for SA (lower in shoot and higher in root) and LJA (higher in root; Table S3). Interaction between condition and treatment for SA was observed in shoots in favor of terrestrial condition and control. Analysis of RDPI for phytohormone contents showed a significant impact of hypomethylating treatment in shoots (Table S2) and lower values for the hypomethylated terrestrial morphotype (Table 1). To summarize, hypomethylation of morphotypes is associated to phytohormone balance changes in aquatic and terrestrial conditions. Phytohormone balance (contents and plasticity) is a sensitive physiological variable essentially affected by condition (-a vs $-t$ ) but also organ (shoots vs roots) and DNA hypomethylation (zebularine vs control).

\section{Metabolomics profiling of hypomethylated aquatic and terrestrial morphotypes}

The amount of several metabolites significantly differed in both shoots and roots depending on morphotypes, experimental conditions (aquatic, terrestrial) and treatments (zebularine-treated plants, control) (Table S4), revealing modifications of the metabolic activities. Condition (-a or $-\mathrm{t}$ ) was the main factor discriminating the metabolic phenotypes of the plants $(P<0.05)$. Specifically, mainly in shoots, plants from aquatic conditions were characterized by a higher amounts of amino acids, including valine, leucine, serine, GABA and aspartic acid, in addition to higher concentrations of phosphoric acid, putrescine, glycerol-3-phosphate and quinic acid $(P<0.05$; Table S4). In plants from terrestrial condition, larger quantities of sugars (fructose, glucose, galactose) were measured in both roots and shoots, and higher levels of polyols (sorbitol and inositol), glyceric acid, gluconolactone, and malic acid in shoots $(P<0.05$; Table S4).

Regarding treatment, the DNA hypomethylation altered the amounts of 10 and 8 metabolites in shoots and roots, respectively ( $P<0.05$; Figs 5 and S4). Six metabolites depicting hypomethylationinduced variability are presented in Fig. 5 (sugar maltose, glucose and fructose, and serine, fumaric and phosphoric acids), while variations of other metabolites are shown in Fig. S4. All metabolites affected by zebularine treatment were analyzed by Metaboanalyst, but no significant metabolomic pathway was identified, probably due to the low number of metabolites concerned here.

Our results show that hypomethylation affected amounts of these metabolites in a complex interaction between the morphotype, condition and organ.

\section{Correlative approach and integrative analysis}


The zebularine treatment discriminated plants from aquatic and terrestrial conditions (numbers of leaves and nodes with buds) as shown on the F1 axis of the PCA, while morphotypes were mainly separated on the second axis (Fig. 6A). Control versus zebularine treated-plants were relatively mixed along the axis. The global DNA methylation percentages were correlated with two variables of the PCA (Fig. S5): the roots ratio ( $\mathrm{Rr} ; \mathrm{r}=0.41$ at $P<0.05$,) and the SA in roots ( $\mathrm{r}=-0.42$ at $P<0.05)$. The main observation was that the hypomethylated aquatic morphotype in aquatic and terrestrial conditions (Am-a-zeb and Am-t-zeb; Fig. 6A) were getting closer to the control terrestrial morphotype in each condition (Tm-a-ctrl and Tm-t-ctrl, respectively).

A hierarchical classification analysis (HP) based on the PCA of morphological data highlighted six clusters mainly for aquatic or terrestrial conditions (Fig. S6) but was unable to clarify the effect of hypomethylation. Thus, calculation of the distances between barycenters and PCA groups were evaluated. The distances of the untreated aquatic morphotype in aquatic conditions (Am-a-ctrl) and the terrestrial morphotype control (Tm-a-ctrl; Am-a-ctrl/Tm-a-ctrl=4.55) were greater than the distance between the hypomethylated aquatic morphotype (Am-a-zeb) and the terrestrial morphotype control (Tm-a-ctrl; Am-a-zeb/Tm-a-ctrl= 3.66), showing a hypomethylation-induced rapprochement of the morphotypes. This finding is also observed from the plants grown in terrestrial condition (Am-tctrl /Tm-t-ctrl = 6.21 vs Am-t-zeb/Tm-t-ctrl= 5.94).

A second PCA with all data incorporating also metabolomic data was run (Fig. S7) and showed a closest proximity between Am-a-zeb and Tm-a-ctrl than between others. The effect of hypomethylation in aquatic conditions is explained principally by differences in water content (WC), shoot ratio ( $\mathrm{Sr}$ ) and some metabolites in shoots such as organic acid (phosphoric acid, aspartic acid), amino acid (phenylalanine) and putrescine (Fig. S7B). For these variables, based on the mean comparison using a tuckey-test, no significant difference was observed after zebularine treatment between Tm-a-ctrl and Am-a-zeb, while significant differences between Tm-a-ctrl and Am-a-ctrl remained ( $P<0.05$ for WC, $P<0.0001$ for Sr).

Altogether, our results suggest that hypomethylation of the aquatic morphotype induces a "terrestrial morphotype-like" situation and mimics the transition to the terrestrial morphotype.

\section{Discussion}

Low genetic and global DNA methylation differentiations between aquatic and terrestrial subpopulations of the invasive L. grandiflora subsp hexapetala plant 
L. grandiflora is known to reproduce essentially by clonal propagation suggesting a low genetic diversity for each population (Richard et al. 2004, Holm et al. 2017) even if it is not a rule (Van Wallendael et al. 2018). However, low genetic variation populations, when it can be assessed, make relevant candidates for testing the role of epigenetic mechanisms in invasive plants (Zhang et al. 2013). We first examined if aquatic and terrestrial morphotypes shared a recent common, local ancestry or descent from different two preadapted subpopulations by estimating their genetic differentiation using 38 SNPs. We also analyzed the genetic distances between all individuals to assess if terrestrial morphotypes originated from a recent single line, or even single clone, with a newlyacquired adaptive genetic capacity. Median $\mathrm{F}_{\mathrm{ST}}$ values observed (0.019) suggested a low genetic differentiation between aquatic and terrestrial morphotypes, well below the threshold value of 0.05 (Hartl and Clark 1997, Frankham et al. 2010), with a recently shared common ancestrality. This alleviates the possibility that fast-terrestrial transition of L. grandiflora subsp hexapetala occurred from a new genetically-based adaptive capacity. The distribution of $\mathrm{F}_{\mathrm{ST}}$ values and the topology of genetic graph (Fig. S1) that we observed are commonly expected to be found by chance in spatiallystructured subpopulations with recent common ancestrality (Wright 1984, Hofet et al. 2009, Bierne et al. 2013). However, we found two SNPs with unusually high $\mathrm{F}_{\mathrm{ST}}$ values. They can be expected under isolation by distance with strong demographical bottleneck in such spreading invasive populations out of equilibrium (Varvio et al. 1986, Rousset 2013), especially considering clonal propagation. But we cannot refute that they may arise by selection with genes implied in adaptation. Further investigations involving spatial genetic structure and genomic approaches should help disentangling between those hypotheses. However, even if such fast-terrestrial transition would have emerged from a newlyacquired genetically-based adaptive capacity hidden in a dominant pattern of isolation-by-distance, it would not exclude an additive, complementary or even dominant epigenetic effect on their phenotypes (Banerjee et al. 2019, Lele et al. 2018).

We thus pushed forward to analyze if those two morphotypes occurring in one genetically homogeneous population may be caused by epigenetic and transcription variations, as commonly observed in invasive plants (Zhang et al. 2013). In plants, DNA methylation is involved in transposon silencing and gene expression, which can change the phenotype in response to environmental variations (Lande 2009, Meyer 2015, Kawakatsu et al. 2016, Bewick and Schmitz 2017, Seymour and Becker 2017). Although epigenomic methods such as whole genome bisulfite sequencing (WGBS) provide detailed information at the genomic scale, they require a complete reference genome that is still lacking in L. grandiflora subsp hexapetala. In addition, this plant has been reported as being a 
decaploid genome leading to a complex genetic analysis (Dandelot et al. 2005). We measured the global DNA methylation (\%mC) using the most approved HPLC technique (Zhu et al. 2013, Kurdyukov and Bullock 2016). Although this approach does not provide DNA methylation characterization at the detailed level of genes and genomic regions, it is a widely used and proven epigenetic indicator in plants accessible from the cell to the population level (Lambé et al. 1997, Causevic et al. 2006, Gourcilleau et al. 2010, Raj et al. 2011, Trap-Gentil et al. 2011, Latzel et al. 2013, Alonso et al. 2015, Garg et al. 2015, Alonso et al. 2016, Le Gac et al. 2018, Sow et al. 2018, Gourcilleau et al. 2019, Le Gac et al. 2019). Here, we found that global methylation levels in $L$. grandiflora subsp hexapetala (estimated genome size around $700 \mathrm{Mb}$, personal communication D. Barloy) was about $28 \%$ of $\mathrm{mC}$ which is five times higher than in Arabidopsis thaliana (5\%; $135 \mathrm{Mb}$ ) and twice as high as in Antirrhinum majus (15\%; 400-500Mb), which is consistent with the relation among global DNA methylation $(\% \mathrm{mC})$ and the genome size reported in angiosperms (Alonso et al. 2015). However, in our study, we could not detect any significant variation in \%mC between morphotypes and conditions, as reported recently in isogenic lines of Antirrhinum majus in different shade avoidance conditions (Gourcilleau et al. 2019). Thus, given the absence of differences in global DNA methylation between morphotypes and conditions, we hypothesize that the phenotypic differences between morphotypes reflect differences in DNA methylation at specific loci. The gold standard epigenomics method is Whole-Genome Bisulfite Sequencing (WGBS), which can provide detailed information on the status of cytosines over the entire genome (Yong et al. 2016) but requires a complete reference genome and represent a financial cost. Further investigations into methylation polymorphism in our system will have actually to use approaches that do not require a reference genome e.g., as methods as epigenome bisulfite sequencing (epiGBS), bisulfite converted restriction site associated DNA sequencing (bsRADseq), Epi RADseq and methylated DNA immunoprecipitation (meDIP) (van Gurp et al. 2016, Trucchi et al. 2016). However, in this instance our objective was to perform an initial epigenetic characterization with a widely used epigenetic indicator (\%mC), and to assess the effect of zebularine treatment.

Zebularine induced hypomethylation on the L. grandiflora subsp hexapetala morphotypes in terrestrial and aquatic conditions

There are several non-exclusive methods for the study of DNA methylation (Kurdyukov and Bullock 2016, Yong et al. 2016) notably in model organisms such as A. thaliana, for which a large number of genetic resources are available. This includes notably manufacturing mutants for enzymes that 
maintain DNA methylation or disrupting DNA via RNAi. However, pharmacological investigations can also be conducted by disrupting de novo methylation with a hypomethylating agent, such as zebularine and 5-azacytidine. This strategy is cost effective and, importantly, does not require genomic resources, and has been successfully implemented not only in model plants such as Arabidopsis thaliana (Baubec et al. 2009, Amoah et al. 2012) but also in many others (Burn et al. 1993, Brock and Davidson 1994, Finnegan et al. 1998, Fieldes et al. 2005, Causevic et al. 2006, Trap-Gentil et al. 2011). Yet, it has never been used in invasive plants. Hypomethylant chemical agents such as zebularine and 5-azacytidine are used in cancer research (Cheng et al. 2004). In addition, there is a renewed use of the hypomethylant chemical agent for the study of DNA methylation and its role in organism responses to the environment (Baubec et al. 2009, Bossdorf et al. 2010, Richards et al. 2010, Hudson et al. 2011, Zhong et al. 2013, Latzel et al. 2016, Osorio-Montalvo et al. 2018, Puy et al. 2018). Zebularine is an inhibitor of methyltransferase, which causes a hypomethylation of de novo tissues. Our study was carried out using concentrations and durations in accordance with the cited literature. We assessed the \%mC using the HPLC method in de novo-formed shoot apexes, as this is where new tissues start their differentiated growth and development on contact with zebularine (Aranda et al. 2017). We found that the 14-day zebularine treatment induces a significant decrease in $\% \mathrm{mC}$ in de novo-formed shoots for all situations (morphotypes $\mathrm{x}$ conditions), and ranging from 4 to 9\% as it was previously reported in Arabidopsis thaliana (Baubec et al. 2009).

Altogether, zebularine is an effective way of reducing the percentage of methylation in plants' de novo-formed tissues. This allows us to generate hypomethylated L. grandiflora morphotypes in both conditions for the first time to assess the impact of DNA hypomethylation on the fast adaptation of invasive plants.

\section{Induced-hypomethylation affects morphotypes and their plasticity proposing that DNA methylation plays a role in the fast transition from aquatic to terrestrial morphotypes.}

In this study, we first reported comparison among the two untreated morphotypes with a lower number of nodes and an elongated morphology, smaller number of leaves and stronger water content in the aquatic morphotype as compared with the terrestrial one. On the contrary, a greater number of leaves and mass of roots significantly characterized the terrestrial morphotype. In parallel, higher quantities of sugars in the terrestrial conditions and amino acids in the aquatic conditions were found. All these findings confirm the conclusions from Billet et al. (2018). Here, we carried out a new analysis with phytohormone quantification and found that phytohormones mainly varied between conditions 
(plasticity) rather than between morphotypes. Thus, ABA, JA and SA were present in greater amounts in terrestrial conditions in good agreement with their role in drought responses (Kohli et al. 2013). Then, hypomethylated morphotypes were compared showing that DNA hypomethylation and growth conditions (-a or -t) positively or negatively affect several morphological, biomass and water content traits, depending on morphotypes. Opposite effects could be observed between the two morphotypes in their original conditions. Hypomethylated morphotypes in both terrestrial and aquatic conditions were shown to exhibit significant variations compared to controls at developmental, hormonal and metabolic levels. Developmental effects induced by variations in DNA methylation have already been largely reported in plants: for example, Baubec et al. (2009) showed a reduction in growth after zebularine treatment in Arabidopsis thaliana. Alonso et al. (2017) observed a decrease in leaf numbers after treatment with 5-azacytidine, and Tatra et al. (2000) reported stem elongation in Stellaria longipes in response to shade by using 5-azacytidine. Our observations are in line with these studies, except that we found a positive effect of hypomethylation on development, such as an increase in leaf and internode numbers.

Furthermore, the measured traits can be associated with the fitness of the plant. Hussner (2009) has shown that any fragment of water primrose can regenerate an entire plant, thus contributing to the species survival. As a result, the number of buds, as well as the size of the plants are important variables in the development of L. grandiflora subsp hexapetala. Biomass is recognized as an important criterion that can be linked to the fitness of the plant (Younginger et al. 2019). As Ludwigia from aquatic and terrestrial conditions exhibit different morphologies, these differences likely contribute to its survival and invasive success.

Another main aspect of our analysis was to combine developmental analysis with measurements of hormone and metabolite levels. Phytohormones contribute not only to plant development, but also to stress responses of the individuals. In addition, there is growing evidence of the existence of a crosstalk between hormonal balance and epigenetic regulation (Yamamuro et al. 2016, Zhang et al. 2016, Campos-Rivero et al. 2017, Maury et al. 2019). Here, we showed that hormonal balances and their plasticity were affected by hypomethylation. In addition, we detected a significant negative correlation between \%mC and SA amount in roots. This is in accordance with Zhang et al. (2016), who reported that the chromatin remodeler DDM1, involved in DNA methylation patterns, promotes hybrid vigor by regulating SA. In addition, connections between DNA methylation and hormone pathways in the shoot apex have recently been highlighted (Lafon-Placette et al. 2018, Le Gac et al. 2018, Maury et al. 2019). Few studies also proposed the existence of relationships 
between phytohormones, metabolites, and epigenetic mechanisms (Latzel et al. 2012, Kooke et al. 2018, Schvartzman et al. 2018). Specifically, Kooke et al. (2018) found some correlations between several Arabidopsis thaliana EpiRILs (Epigenetic Recombinant Inbred Lines) and some secondary metabolites. Shen et al. (2016) summarized the interaction between metabolic/redox signaling and epigenetics, in terms of plant adaptation to environmental conditions, suggesting a "bi-directional interplay” of epigenetics and metabolism. Here, we found several metabolites (amino acids, sugars and organic acids) affected by hypomethylation, and six of them could be correlated to the \%mC levels. However, the complex interplay among epigenetics and metabolism needs more insight before being clearly interpreted.

Our fine characterization of the hypomethylation effects on the two invasive morphotypes in terrestrial and aquatic conditions at developmental, hormonal and metabolic levels allows us to carry out an integrative approach using PCA. As we hypothesized, DNA hypomethylation impacted aquatic and terrestrial morphotypes of L. grandiflora subsp hexapetala differently in response to the two conditions. The main outcome of this integrative analysis was that inducing hypomethylation on the aquatic morphotype gives a terrestrial morphotype-'like’ phenotype. Altogether, our data showed that hypomethylation of the invasive aquatic morphotype mimics the terrestrial fast transition suggesting an implication of the epigenome in the appearance of this new terrestrial invasive morphotype. However, different scenarios can be discussed here. The implication of DNA methylation could be causal through the control of gene expression or transposable element activation as well as a downstream marker of changes resulting from genetic changes (Banerjee et al. 2019, Marin et al. 2019). In addition, our data showed a weak genetic population structuration, but we cannot exclude that the terrestrial morphotype has been selected from the aquatic population with some genetic diversity (for example transposable elements) and become successful in terrestrial conditions. It is also possible that interactions between genetics and epigenetics at specific loci could be involved. Indeed, plant phenotype can reflect past environments of parents or even grandparents due to transgenerational effects as proposed in the clonal plant Trifolium repens (Rendina González et al. 2018). There is potential for environment-induced, heritable DNA methylation to exist in addition to other parental effects (Rendina González et al. 2018)

A future challenge will be to disentangle genetic and epigenetic effects notably for invasive plants (Banerjee et al. 2019, Marin et al. 2019). One solution concerning clonal invasive plants such as L. grandiflora subsp hexapetala could be to focus on a single clone vegetatively propagated for each morphotype and to develop an epi/genomic strategy in parallel to the creation of genomic resources 
(genome and transcriptome). Barnejee et al. (2019) present an experimental framework for the characterization of the three-way relationship between environmental cue, phenotypic plasticity and epigenetic changes. They recommend also "combining trait and molecular data and including comparative analysis of fitness functions between native and introduced ranges of a species and explore adaptive differentiation in invaders, while accounting for non-adaptive evolutionary changes”. It is also important to evaluate the combined roles of epigenetics and transposable elements on a genomic scale, which could be key sources of flexibility for invasive species during the colonisation of new environment (Gao et al. 2010, Richards et al. 2012, Xie et al. 2015, Marin et al. 2019).

\section{Author contributions}

J.G., S.M. and D.B. designed and conducted the research. J.G., D.V. and D.B. performed zebularin treatment and measured morphological traits. A.D. and S.M. carried out DNA methylation analysis, S.C. quantified phytohormones, D.R. with J.G. realized metabolomic analysis and S.S. with L.P. performed SNP and genetic differentiation analyses. M.P.E. and J.G. done the statistical analyses. J.G., S.M. and D.B. analyzed the data, conceived the idea and the initial structure of the manuscript. All authors have read and approved the final manuscript.

Acknowledgments - This work was supported by the "INRA Département EFPA" (grant PI EFPA2016 to D.B and S.M.), the RTP3E CNRS (http://rtp-3e.wixsite.com/rt3e; Cristoph Grunau, University Perpignan), the ONEMA (“Office National de l'Eau et des Milieux Aquatiques”), the "Région Bretagne and INRA Département EFPA” (PhD grant to J.G.). The IJPB benefits from the support of Saclay Plant Sciences-SPS (ANR-10-LABX-0040-SPS). This work has benefited from the support of IJPB's Plant Observatory technological platforms. The authors thank the Experimental Unit of Aquatic Ecology and Ecotoxicology (U3E) 1036, INRAE, which is part of the research infrastructure Analysis and Experimentations on Ecosystems-France, for help with the maintenance of plants.

\section{Data availability statement}

The data that support the findings of this study are available on request from the corresponding author.

\section{References}


Allis CD, Jenuwein T (2016) The molecular hallmarks of epigenetic control. Nat Rev Genet 17: 487500

Alonso C, Medrano M, Pérez R, Bazaga P, Herrera CM (2017) Tissue-Specific Response to Experimental Demethylation at Seed Germination in the Non-Model Herb Erodium cicutarium. Epigenomes 1: 16

Alonso C, Pérez R, Bazaga P, Herrera CM (2015) Global DNA cytosine methylation as an evolving trait: phylogenetic signal and correlated evolution with genome size in angiosperms. Front Genet 6: 4 .

Alonso C, Pérez R, Bazaga P, Medrano M, Herrera CM (2016) MSAP markers and global cytosine methylation in plants: a literature survey and comparative analysis for a wild-growing species. Mol Ecol Resour 16: 80-90

Amoah S, Kurup S, Rodriguez Lopez C, Welham SJ, Powers SJ, Hopkins CJ, Wilkinson MJ, King GJ (2012) A Hypomethylated population of Brassica rapa for forward and reverse Epi-genetics. BMC Plant Biol 12: 193

Aranda J, Attana F, Tuñón I (2017) Molecular Mechanism of Inhibition of DNA Methylation by Zebularine. ACS Catal 7: 1728-1732

Avramova Z (2019) Defence-related priming and responses to recurring drought: Two manifestations of plant transcriptional memory mediated by the ABA and JA signalling pathways. Plant Cell Environ 42: 983-997

Banerjee AK, Guo W, Huang Y (2019) Genetic and epigenetic regulation of phenotypic variation in invasive plants - linking research trends towards a unified framework. NeoBiota 49: 77-103

Baubec T, Pecinka A, Rozhon W, Mittelsten Scheid O (2009) Effective, homogeneous and transient interference with cytosine methylation in plant genomic DNA by zebularine. Plant J 57: 542-554

Baulcombe DC, Dean C (2014) Epigenetic Regulation in Plant Responses to the Environment. Cold Spring Harb Perspect Biol. 
Bewick AJ, Schmitz RJ (2017) Gene body DNA methylation in plants. Curr Opin Plant Biol 36: 103110

Bierne N, Roze D, Welch JJ (2013) Pervasive selection or is it...? Why are FST outliers sometimes so frequent? Mol Ecol 22: 2061-2064

Billet K, Genitoni J, Bozec M, Renault D, Barloy D (2018) Aquatic and terrestrial morphotypes of the aquatic invasive plant, Ludwigia grandiflora , show distinct morphological and metabolomic responses. Ecol Evol 8: 2568-2579

Bossdorf O, Arcuri D, Richards CL, Pigliucci M (2010) Experimental alteration of DNA methylation affects the phenotypic plasticity of ecologically relevant traits in Arabidopsis thaliana. Evol Ecol 24: $541-553$

Bräutigam K, Vining KJ, Lafon-Placette C, Fossdal CG, Mirouze M, Marcos JG, Fluch S, Fraga MF, Guevara MÁ, Abarca D, et al (2013) Epigenetic regulation of adaptive responses of forest tree species to the environment. Ecol Evol 3: 399-415

Brock RD, Davidson JL (1994) 5-azacytidine and gamma rays partially substitute for cold treatment in vernalizing winter wheat. Environ Exp Bot 34: 195-199

Burn JE, Bagnall DJ, Metzger JD, Dennis ES, Peacock WJ (1993) DNA methylation, vernalization, and the initiation of flowering. Proc Natl Acad Sci USA 90: 287-291

Campos-Rivero G, Osorio-Montalvo P, Sánchez-Borges R, Us-Camas R, Duarte-Aké F, De-la-Peña C (2017) Plant hormone signaling in flowering: An epigenetic point of view. J Plant Physiol 214: 16-27

Causevic A, Gentil M-V, Delaunay A, El-Soud WA, Garcia Z, Pannetier C, Brignolas F, Hagège D, Maury S (2006) Relationship between DNA methylation and histone acetylation levels, cell redox and cell differentiation states in sugarbeet lines. Planta 224: 812-827

Cheng JC, Yoo CB, Weisenberger DJ, Chuang J, Wozniak C, Liang G, Marquez VE, Greer S, Orntoft TF, Thykjaer T, et al (2004) Preferential response of cancer cells to zebularine. Cancer Cell 6: 151158 
Chown SL, Slabber S, McGeoch MA, Janion C, Leinaas HP (2007) Phenotypic plasticity mediates climate change responses among invasive and indigenous arthropods. Proc R Soc B: 274: 2531-2537

Conde D, Le Gac A-L, Perales M, Dervinis C, Kirst M, Maury S, González-Melendi P, Allona I (2017) Chilling-responsive DEMETER-LIKE DNA demethylase mediates in poplar bud break: Role of active DNA demethylase in trees’ bud break. Plant Cell Environ 40: 2236-2249

Core Team (2018) R: A language and environment for statistical computing. R Foundation for Statistical Computing, Vienna, Austria. URL https://www.R-project.org/

Crisp PA, Ganguly D, Eichten SR, Borevitz JO, Pogson BJ (2016) Reconsidering plant memory: Intersections between stress recovery, RNA turnover, and epigenetics. Sci Adv 2: e1501340e1501340

Daehler CC (2003) Performance Comparisons of Co-Occurring Native and Alien Invasive Plants: Implications for Conservation and Restoration. Annu Rev Ecol Evol Syst 34: 183-211

Dandelot S, Verlaque R, Dutartre A, Cazaubon A (2005) Ecological, Dynamic and Taxonomic Problems Due to Ludwigia (Onagraceae) in France. Hydrobiologia 551: 131-136

Davidson AM, Jennions M, Nicotra AB (2011) Do invasive species show higher phenotypic plasticity than native species and, if so, is it adaptive? A meta-analysis: Invasive species have higher phenotypic plasticity. Ecol Lett 14: 419-431

Duncan EJ, Gluckman PD, Dearden PK (2014) Epigenetics, plasticity, and evolution: How do we link epigenetic change to phenotype? J Exp Zool B: 322: 208-220

Dyer RJ (2015) Population graphs and landscape genetics. Annu Rev Ecol Evol Syst 46: 327-342

Early R, Bradley BA, Dukes JS, Lawler JJ, Olden JD, Blumenthal DM, Gonzalez P, Grosholz ED, Ibañez I, Miller LP, et al (2016) Global threats from invasive alien species in the twenty-first century and national response capacities. Nat Commun 7: 12485

Fang C, Zhang H, Wan J, Wu Y, Li K, Jin C, Chen W, Wang S, Wang W, Zhang H, et al (2016) Control of Leaf Senescence by an MeOH-Jasmonates Cascade that Is Epigenetically Regulated by OsSRT1 in Rice. Mol Plant 9: 1366-1378 
Fieldes MA, Schaeffer SM, Krech MJ, Brown JCL (2005) DNA hypomethylation in 5-azacytidineinduced early-flowering lines of flax. Theor Appl Genet 111: 136-149

Finnegan EJ, Genger RK, Peacock WJ, Dennis ES (1998) DNA METHYLATION IN PLANTS. Annu Rev Plant Physiol Plant Mol Biol 49: 223-247

Frankham R (2010) Challenges and opportunities of genetic approaches to biological conservation. Biological Conservation,Volume 143, Issue 9, Pages 1919-1927, ISSN 0006-3207

Frankham R, Ballou JD, Briscoe DA (2010) Introduction to Conservation Genetics 2nd edition. Cambridge University Press: Cambridge, UK

Gao L, Geng Y, Li B, Chen J, Yang J (2010) Genome-wide DNA methylation alterations of Alternanthera philoxeroides in natural and manipulated habitats: implications for epigenetic regulation of rapid responses to environmental fluctuation and phenotypic variation: Environmental epigenetics of A. philoxeroides. Plant Cell Environ 33: 1820-1827

Gao X, Martin ER (2009) Using allele sharing distance for detecting human population stratification. Hum Hered 68: 182-191

Garg R, Narayana Chevala V, Shankar R, Jain M (2015) Divergent DNA methylation patterns associated with gene expression in rice cultivars with contrasting drought and salinity stress response. Sci Rep 5: 14922

Godoy O, Valladares F, Castro-Díez P (2011) Multispecies comparison reveals that invasive and native plants differ in their traits but not in their plasticity: Phenotypic plasticity and invasiveness. Funct Ecol 25: 1248-1259

Gourcilleau D, Bogeat-Triboulot M-B, Thiec DL, Lafon-Placette C, Delaunay A, El-Soud WA, Brignolas F, Maury S (2010) DNA methylation and histone acetylation: genotypic variations in hybrid poplars, impact of water deficit and relationships with productivity. Ann For Sci 67: 208

Gourcilleau D, Mousset M, Latutrie M, Marin S, Delaunay A, Maury S, Pujol B (2019) Assessing Global DNA Methylation Changes Associated with Plasticity in Seven Highly Inbred Lines of Snapdragon Plants (Antirrhinum majus). Genes 10: 256 
Guo JE, Hu Z, Yu X, Li A, Li F, Wang Y, Tian S, Chen G (2018) A histone deacetylase gene, SIHDA3, acts as a negative regulator of fruit ripening and carotenoid accumulation. Plant Cell Rep 37: 125-135

van Gurp TP, Wagemaker NCAM, Wouters B, Vergeer P, Ouborg JNJ, Verhoeven KJF (2016) epiGBS: reference-free reduced representation bisulfite sequencing. Nat Methods 13: 322-324

Hardy OJ (2016) Population genetics of autopolyploids under a mixed mating model and the estimation of selfing rate. Mol Ecol Resour 16: 103-117

Hartl DL, Clark GC (1997) Principles of Population Genetics. Sinauer Associates, Sunderland. 542p

Haury J, Druel A, Cabral T, Paulet Y, Bozec M, Coudreuse J (2014) Which adaptations of some invasive Ludwigia spp. (Rosidae, Onagraceae) populations occur in contrasting hydrological conditions in Western France? Hydrobiologia 737: 45-56

Hofer T, Ray N, Wegmann D, Excoffier L (2009) Large allele frequency differences between human continental groups are more likely to have occurred by drift during range expansions than by selection. Ann Hum Genet 73: 95-108

Holm A-K, Elameen A, Oliver BW, Brandsaeter LO, Fløistad IS, Brurberg MB (2017) Low genetic variation of invasive Fallopia spp. in their northernmost European distribution range. Ecol Evol 8. 10.1002/ece3.3703.

Hudson K, Luo S, Hagemann N, Preuss D (2011) Changes in Global Gene Expression in Response to Chemical and Genetic Perturbation of Chromatin Structure. PLoS One 6: e20587

Hudson K, Luo S, Hagemann N, Preuss D (2011) Changes in global gene expression in response to chemical and genetic perturbation of chromatin structure. PLoS One 6: e20587

Hussner A, Windhaus M, Starfinger U (2016) From weed biology to successful control: an example of successful management of Ludwigia grandiflora in Germany. Weed Res 56: 434-441

Hussner A (2009) Growth and photosynthesis of four invasive aquatic plant species in Europe. Weed Res 49: 506-515 
Kawakatsu T, Huang S-SC, Jupe F, Sasaki E, Schmitz RJ, Urich MA, Castanon R, Nery JR, Barragan C, He Y, et al (2016) Epigenomic Diversity in a Global Collection of Arabidopsis thaliana Accessions. Cell 166: 492-505

van Kleunen M, Dawson W, Essl F, Pergl J, Winter M, Weber E, Kreft H, Weigelt P, Kartesz J, Nishino M, et al (2015) Global exchange and accumulation of non-native plants. Nature 525: 100-103

Kohli A, Sreenivasulu N, Lakshmanan P, Kumar PP (2013) The phytohormone crosstalk paradigm takes center stage in understanding how plants respond to abiotic stresses. Plant Cell Rep 32: 945-957

Kooke R, Johannes F, Wardenaar R, Becker F, Etcheverry M, Colot V, Vreugdenhil D, Keurentjes JJB (2015) Epigenetic Basis of Morphological Variation and Phenotypic Plasticity in Arabidopsis thaliana. Plant Cell 27: 337-348

Kooke R, Morgado L, Becker FFM, van Eekelen H, Hazarika R, Zheng Q, de Vos RCH de, Johannes F, Keurentjes JJB (2018) Epigenetic mapping of the Arabidopsis metabolome reveals mediators of the epigenotype-phenotype map. Genome Res gr.232371.117

Kurdyukov S, Bullock M (2016) DNA Methylation Analysis: Choosing the Right Method. Biology 5: 3

Lafon-Placette C, Faivre-Rampant P, Delaunay A, Street N, Brignolas F, Maury S (2013), Methylome of DNase I sensitive chromatin in Populus trichocarpa shoot apical meristematic cells: a simplified approach revealing characteristics of gene-body DNA methylation in open chromatin state. New Phytol 197: 416-430

Lafon-Placette C, Le Gac A-L, Chauveau D, Segura V, Delaunay A, Lesage-Descauses M-C, Hummel I, Cohen D, Jesson B, Le Thiec D, et al (2018) Changes in the epigenome and transcriptome of the poplar shoot apical meristem in response to water availability affect preferentially hormone pathways. J Exp Bot 69: 537-551

Lamarque LJ, Porté AJ, Eymeric C, Lasnier J-B, Lortie CJ, Delzon S (2013) A Test for Pre-Adapted Phenotypic Plasticity in the Invasive Tree Acer negundo L. PLoS One 8: e74239 
Lambé P, Mutambel HSN, Fouché J-G, Deltour R, Foidart J-M, Gaspar T (1997) DNA methylation as a key process in regulation of organogenic totipotency and plant neoplastic progression? In Vitro Cell. Dev Biol Plant 33: 155-162

Lambert E, Dutartre A, Coudreuse J, Haury J (2010) Relationships between the biomass production of invasive Ludwigia species and physical properties of habitats in France. Hydrobiologia 656: 173-186

Lämke J, Bäurle I (2017) Epigenetic and chromatin-based mechanisms in environmental stress adaptation and stress memory in plants. Genome Biol 18: 124

Lande R (2009) Adaptation to an extraordinary environment by evolution of phenotypic plasticity and genetic assimilation. J Evol Biol 22: 1435-1446

Latzel V, Allan E, Bortolini Silveira A, Colot V, Fischer M, Bossdorf O (2013) Epigenetic diversity increases the productivity and stability of plant populations. Nat Commun 4: 2875

Latzel V, Rendina González AP, Rosenthal J (2016) Epigenetic Memory as a Basis for Intelligent Behavior in Clonal Plants. Front Plant Sci 7: 1354

Latzel V, Zhang Y, Karlsson Moritz K, Fischer M, Bossdorf O (2012) Epigenetic variation in plant responses to defence hormones. Ann Bot 110: 1423-1428

Le Gac A-L, Delaunay A, Maury S, Lafon-Placette C (2019) Developmental, genetic and environmental variations of global DNA methylation in the first leaves emerging from the shoot apical meristem in poplar trees. Plant Signal Behav 14: 1596717

Le Gac A-L, Lafon-Placette C, Chauveau D, Segura V, Delaunay A, Fichot R, Marron N, Le Jan I, Berthelot A, Bodineau G, et al (2018) Winter-dormant shoot apical meristem in poplar trees shows environmental epigenetic memory. J Exp Bot 69: 4821-4837

Lele L, Ning D, Cuiping P, Xiao G, Weihua G (2018) Genetic and epigenetic variations associated with adaptation to heterogeneous habitat conditions in a deciduous shrub. Ecol Evol 8: 2594-2606

Li W, Chen W, Qi X, Wang Q, Chen J (2013) Variation of cytosine methylation in response to water availability in two contrasting growth types of an amphibious plant Alternanthera philoxeroides. Biochem Syst Ecol 50: 175-181 
Li Y, Kumar S, Qian W (2018) Active DNA demethylation: mechanism and role in plant development. Plant Cell Rep 37: 77-85

Marin P, Genitoni J, Barloy D, Maury S, Gibert P, Ghalambor CK, Vieira C (2019) Biological invasion: The influence of the hidden side of the (epi)genome. Funct Ecol 34: 385- 400

Matzek V (2012) Trait Values, Not Trait Plasticity, Best Explain Invasive Species’ Performance in a Changing Environment. PLoS One 7: e48821

Mauch-Mani B, Baccelli I, Luna E, Flors V (2017) Defense Priming: An Adaptive Part of Induced Resistance. Annu. Rev. Plant Biol 68: 485-512

Maury S, Sow MD, Le Gac A-L, Genitoni J, Lafon-Placette C, Mozgova I (2019) Phytohormone and chromatin Crosstalk: The Missing Link For Developmental Plasticity? Front Plant Sci doi: 10.3389/fpls.2019.00395

Meyer P (2018) Chapter One - Epigenetics - A Historical Perspective. In M Mirouze, E Bucher, P Gallusci, eds, Advances in Botanical Research. Academic Press, pp 1-19

Meyer P (2015) Epigenetic variation and environmental change: Fig. 1. J. Exp. Bot. 66: 3541-3548

Morris MRJ (2014) Plasticity-Mediated Persistence in New and Changing Environments. Int J Evol Biol 2014: 1-18

Mountain JL, Ramakrishnan U (2005) Impact of human population history on distributions of individual-level genetic distance. Hum Genomics 2: 4-19

Nesom G, Kartesz J (2000) Observations on the Ludwigia uruguayensis Complex (Onagraceae) in the United States. Castanea 65: 123-125

Osorio-Montalvo P, Sáenz-Carbonell L, De-la-Peña C (2018) 5-Azacytidine: A Promoter of Epigenetic Changes in the Quest to Improve Plant Somatic Embryogenesis. Int J Mol Sci 19: 3182

Pigliucci M (2005) Evolution of phenotypic plasticity: where are we going now? Trends Ecol Evol 20: 481-486 
Puy J, Dvořáková H, Carmona CP, de Bello F, Hiiesalu I, Latzel V (2018) Improved demethylation in ecological epigenetic experiments: Testing a simple and harmless foliar demethylation application. Methods Ecol Evol 9: 744-753

Raj S, Bräutigam K, Hamanishi ET, Wilkins O, Thomas BR, Schroeder W, Mansfield SD, Plant AL, Campbell MM (2011) Clone history shapes Populus drought responses. Proc Natl Acad Sci USA 108: $12521-12526$

Rendina González AP, Preite V, Verhoeven KJF, Latzel V (2018) Transgenerational Effects and Epigenetic Memory in the Clonal Plant Trifolium repens. Front Plant Sci 9:1677

Rey O, Danchin E, Mirouze M, Loot C, Blanchet S (2016) Adaptation to Global Change: A Transposable Element-Epigenetics Perspective. Trends Ecol Evol. 31: 514-526

Richards CL, Alonso C, Becker C, Bossdorf O, Bucher E, Colomé-Tatché M, Durka W, Engelhardt J, Gaspar B, Gogol-Döring A, et al (2017) Ecological plant epigenetics: Evidence from model and nonmodel species, and the way forward. Ecol Lett 20: 1576-1590

Richards CL, Bossdorf O, Pigliucci M (2010) What Role Does Heritable Epigenetic Variation Play in Phenotypic Evolution? BioScience 60: 232-237

Richards CL, Schrey AW, Pigliucci M (2012) Invasion of diverse habitats by few Japanese knotweed genotypes is correlated with epigenetic differentiation. Ecol Lett 15: 1016-1025

Richards EJ (2006) Inherited epigenetic variation — revisiting soft inheritance. Nat Rev Genet 7: 395-401

Richards CL, Hamrick JL, Donovan LA, Mauricio R (2004) Unexpectedly high clonal diversity of two salt marsh perennials across a severe environmental gradient. Ecol Lett 7: 1155-1162

Rozenfeld AF, Arnaud-Haond S, Hernández-García E, Eguíluz VM, Matías MA, Serrão E, Duarte CM (2007) Spectrum of genetic diversity and networks of clonal organisms. J R Soc Interface 4: 10931102 
Rozenfeld AF, Arnaud-Haond S, Hernández-García E, Eguíluz VM, Serrão EA, Duarte CM (2008) Network analysis identifies weak and strong links in a metapopulation system. Proc Natl Acad Sci USA 105: 18824-18829

Rousset F (2013) Genetic Structure and Selection in Subdivided Populations. Princeton University Press, Princeton, NJ. 264 pages. ISBN: 9781400847242.

Roux CL, Prete SD, Boutet-Mercey S, Perreau F, Balagué C, Roby D, Fagard M, Gaudin V (2014) The hnRNP-Q Protein LIF2 Participates in the Plant Immune Response. PLOS One 9: e99343

Russell Lenth (2018) emmeans: Estimated Marginal Means, aka Least-Squares Means. R package version 1.2.4. https://CRAN.R-project.org/package=emmeans

Sahu PP, Pandey G, Sharma N, Puranik S, Muthamilarasan M, Prasad M (2013) Epigenetic mechanisms of plant stress responses and adaptation. Plant Cell Rep 32: 1151-1159

Schmid MW, Heichinger C, Coman Schmid D, Guthörl D, Gagliardini V, Bruggmann R, Aluri S, Aquino C, Schmid B, Turnbull LA, et al (2018) Contribution of epigenetic variation to adaptation in Arabidopsis. Nat Commun 9: 4446

Schvartzman JM, Thompson CB, Finley LWS (2018) Metabolic regulation of chromatin modifications and gene expression. J Cell Biol 217: 2247-2259

Serra A-A, Nuttens A, Larvor V, Renault D, Couée I, Sulmon C, Gouesbet G (2013) Low environmentally relevant levels of bioactive xenobiotics and associated degradation products cause cryptic perturbations of metabolism and molecular stress responses in Arabidopsis thaliana. J Exp Bot 64: 2753-2766

Sexton JP, Mckay JK, Sala A (2002) Plasticity and genetic diversity may allow saltcedar to invade cold climates in North America. Ecol Appl 12: 9

Seymour DK, Becker C (2017) The causes and consequences of DNA methylome variation in plants. Curr Opin Plant Biol 36: 56-63

Shen Y, Issakidis-Bourguet E, Zhou D-X (2016) Perspectives on the interactions between metabolism, redox, and epigenetics in plants. J Exp Bot 67: 5291-5300 
Sow MD, Segura V, Chamaillard S, Jorge V, Delaunay A, Lafon-Placette C, Fichot R, FaivreRampant P, Villar M, Brignolas F, et al (2018) Narrow-sense heritability and PST estimates of DNA methylation in three Populus nigra L. populations under contrasting water availability. Tree Genet Genom 14: 78

Stevens EL, Heckenberg G, Roberson ED, Baugher JD, Downey TJ, Pevsner J (2011) Inference of relationships in population data using identity-by-descent and identity-by-state. PLoS Genet 7: e1002287

Tatra GS, Miranda J, Chinnappa CC, Reid DM (2000) Effect of light quality and 5-azacytidine on genomic methylation and stem elongation in two ecotypes of Stellaria longipes. Physiol Plant 109: 313-321

Templeton A.R. (2006) Population Genetics and Microevolutionary Theory. Hoboken (New Jersey): Wiley-Liss. 705 p. ISBN: 0-471-40951-0

Teyssier C, Maury S, Beaufour M, Grondin C, Delaunay A, Le Metté C, Ader K, Cadene M, Label P, Lelu-Walter M-A (2014) In search of markers for somatic embryo maturation in hybrid larch ( Larix $\times$ eurolepis ): global DNA methylation and proteomic analyses. Physiol Plant 150: 271-291

Theoharides KA, Dukes JS (2007) Plant invasion across space and time: factors affecting nonindigenous species success during four stages of invasion. New Phytol 176: 256-273

Trap-Gentil M-V, Hébrard C, Lafon-Placette C, Delaunay A, Hagège D, Joseph C, Brignolas F, Lefebvre M, Barnes S, Maury S (2011) Time course and amplitude of DNA methylation in the shoot apical meristem are critical points for bolting induction in sugar beet and bolting tolerance between genotypes. J Exp Bot 62: 2585-2597

Tricker PJ (2015) Transgenerational inheritance or resetting of stress-induced epigenetic modifications: two sides of the same coin. Front Plant Sci 6: 699

Trucchi E, Mazzarella AB, Gilfillan GD, Lorenzo MT, Schönswetter P, Paun O (2016) BsRADseq: screening DNA methylation in natural populations of non-model species. Mol Ecol 25: 1697-1713

Trussell GC, Smith LD (2000) Induced defenses in response to an invading crab predator: An explanation of historical and geographic phenotypic change. Proc Natl Acad Sci USA 97: 2123-2127 
Xia J, Sinelnikov IV, Han B, Wishart DS (2015) MetaboAnalyst 3.0--making metabolomics more meaningful. Nucleic Acids Res 43: W251-257

Valladares F, Sanchez-Gomez D, Zavala M-A (2006) Quantitative estimation of phenotypic plasticity: bridging the gap between the evolutionary concept and its ecological applications. J Ecol 94: 11031116

VanWallendael A, Hamann E, Franks SJ (2018) Evidence for plasticity, but not local adaptation, in invasive Japanese knotweed (Reynoutria japonica) in North America. Ecol Evol 32: 395-410

Varvio S, Chakraborty R, Nei M (1986) Genetic variation in subdivided populations and conservation genetics. Heredity 57: 189-198

Wright S (1984) Evolution and the Genetics of Populations, Volume 4: Variability Within and Among Natural Populations. University of Chicago Press, 590 p

Xie HJ, Li H, Liu D, Dai WM, He JY, Lin S, Duan H, Liu LL, Chen SG, Song XL, et al (2015) ICE1 demethylation drives the range expansion of a plant invader through cold tolerance divergence. Mol Ecol 24: 835-850

Yamamuro C, Zhu J-K, Yang Z (2016) Epigenetic Modifications and Plant Hormone Action. Mol Plant 9: 57-70

Yong W-S, Hsu F-M, Chen P-Y (2016) Profiling genome-wide DNA methylation. Epigenet Chromatin 9: 26

Younginger BS, Sirová D, Cruzan MB, Ballhorn DJ (2017) Is biomass a reliable estimate of plant fitness? Appl Plant Sci 5: 1600094

Zhang Q, Li Y, Xu T, Srivastava AK, Wang D, Zeng L, Yang L, He L, Zhang H, Zheng Z, et al (2016) The chromatin remodeler DDM1 promotes hybrid vigor by regulating salicylic acid metabolism. Cell Discov 2: 16027

Zhang Y-Y, Fischer M, Colot V, Bossdorf O (2013) Epigenetic variation creates potential for evolution of plant phenotypic plasticity. New Phytol 197: 314-322 
Zhong S, Fei Z, Chen Y-R, Zheng Y, Huang M, Vrebalov J, McQuinn R, Gapper N, Liu B, Xiang J, et al (2013) Single-base resolution methylomes of tomato fruit development reveal epigenome modifications associated with ripening. Nat Biotechnol 31: 154-159

Zhu R, Shevchenko O, Ma C, Maury S, Freitag M, Strauss SH (2013) Poplars with a PtDDM1-RNAi transgene have reduced DNA methylation and show aberrant post-dormancy morphology. Planta 237: 1483-1493

\section{Supporting information}

Additional supporting information may be found online in the Supporting Information section at the end of the article.

Table S1. Morphological biomass and water content variables in aquatic and terrestrial morphotypes.

Table S2. Phenotypic plasticity (RDPI) of morphological traits in aquatic and terrestrial morphotypes.

Table S3. Phytohormones quantities in roots and shoots in aquatic and terrestrial morphotypes.

Table S4. Metabololites amounts in shoots and roots in aquatic and terrestrial morphotypes.

Fig. S1. Minimum spanning graph of the genetic relatedness.

Fig. S2. Morphological variables measured in aquatic and terrestrial morphotypes.

Fig. S3. Phytohormones measured in aquatic and terrestrial morphotypes.

Fig. S4. Metabolites measured in aquatic and terrestrial morphotypes (Am and Tm).

Fig. S5. Correlation matrix between morphological, phytohormone and metabolites variables and global DNA methylation percentages.

Fig. S6. Cluster dendrogram of morphological and phytohormones variables.

Fig. S7. Principal Component analysis (PCA) of global methylation percentages, morphological traits, phytohormones and metabolites in aquatic and terrestrial morphotypes.

\section{Figure legends:}

Fig. 1. Distribution of unbiased pairwise $F_{S T}$ values per locus between aquatic and terrestrial subpopulations of L. grandiflora subsp. hexapetala. Overall median value: 0.019 [1 ${ }^{\text {st }}$ quartile: 0.009 ; $3^{\text {rd }}$ quartile: 0.107$]$. 
Fig. 2. Global DNA methylation percentages in de novo-formed shoot of aquatic and terrestrial morphotypes (white and black, respectively) in aquatic and terrestrial conditions with or without 14 days of zebularine treatment ('zeb' for $150 \mu \mathrm{M}$ of zebularine and ctrl for control). Bars represent the mean value of three biological replicates with their standard errors. Thanks to a Tuckey HSD test based on the mean difference between groups, one or more letters are assigned to each group. Two groups sharing one letter have no significant difference.

Fig. 3. Phenotype of hypomethylated aquatic and terrestrial morphotypes (white and black, respectively) of Ludwigia grandiflora grown in terrestrial or aquatic conditions. (A) Pictures of control and zebularine treated plants in each condition. (B) Number of leaves, of internodes, water content and fress mass of roots. Bars represent the mean value of ten biological replicates with their standard errors. Letters are assigned to groups thanks to a Tuckey HSD test. Two groups sharing one letter have no significant difference. Supplementary data for statistics are presented in Table S1.

Fig. 4. Phytohormone quantities in roots and shoots of aquatic and terrestrial morphotypes (white and black) of Ludwigia grandiflora grown in terrestrial or aquatic conditions. Bars represent the mean value of three biological replicates with their standard errors. Letters are assigned to groups thanks to a Tuckey HSD test. Two groups sharing one letter have no significant difference. Shoots values are presented at the top and roots at the bottom. Supplementary data for statistics are presented in Table S3.

Fig. 5. Metabolite (maltose, serine, fructose, phosphoric acid, glucose, fumaric acid) quantities in roots and shoots of aquatic and terrestrial morphotypes (white and black) of Ludwigia grandiflora grown in terrestrial and aquatic conditions. Bars represent the mean value of three biological replicates with their standard errors. Shoots values are presented at the top and roots at the bottom. Letters are assigned to groups thanks to a Tuckey HSD test. Two groups sharing one letter have no significant difference. Supplementary data for statistics are presented in Table S4.

Fig. 6. Principal component analysis (PCA) representation allowing the characterization of the morphological and physiological variability of hypomethylated (zeb) or not (ctrl) aquatic and terrestrial morphotypes in aquatic (Am-a, Tm-a) and terrestrial (Am-t, Tm-t) conditions. (A) Individual factor map. Each data point represents one biological repeat. (B) Variables factor map. Morphological 
variables represented are number of leaves (nbL), length of internodes (LI), number of nodes (nbI), number of nodes with roots (nbNR), number of buds (nbB), fresh and dry mass of roots and shoots (FMS, FMR, DMS and DMR), shoots and roots ratio (FMS/DMS = Sr; FMR/DMR $=$ Rr), water content (WC). Phytohormones represented are auxin (IAA), salicylic acid (SA) and leucine jasmonyl acid (JL) in shoots and in roots (IAAr, SAr, JLr). Global DNA methylation percentages are indicated by $\% \mathrm{mC}$. 


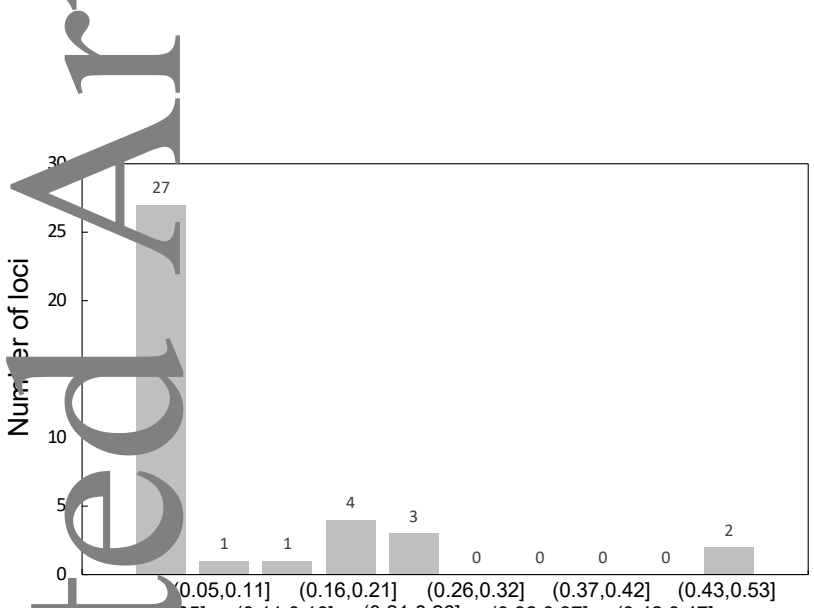
.05] $\quad(0.11,0.16] \quad(0.21,0.26] \quad(0.32,0.37] \quad(0.42,0.47]$

Fst 
Aquatic morphotype

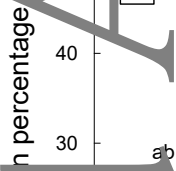

Terrestrial morphotype

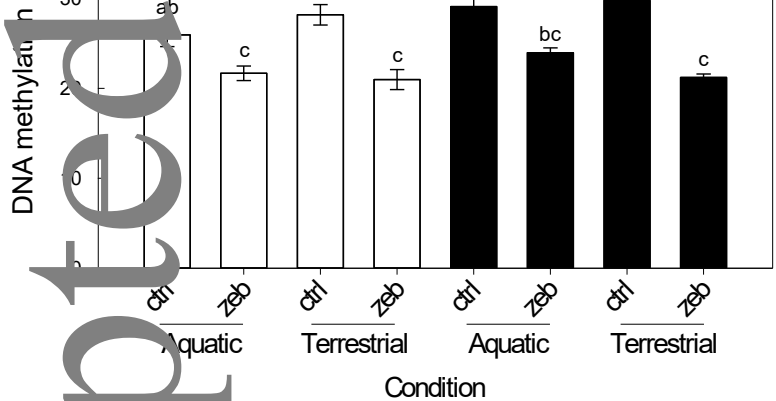



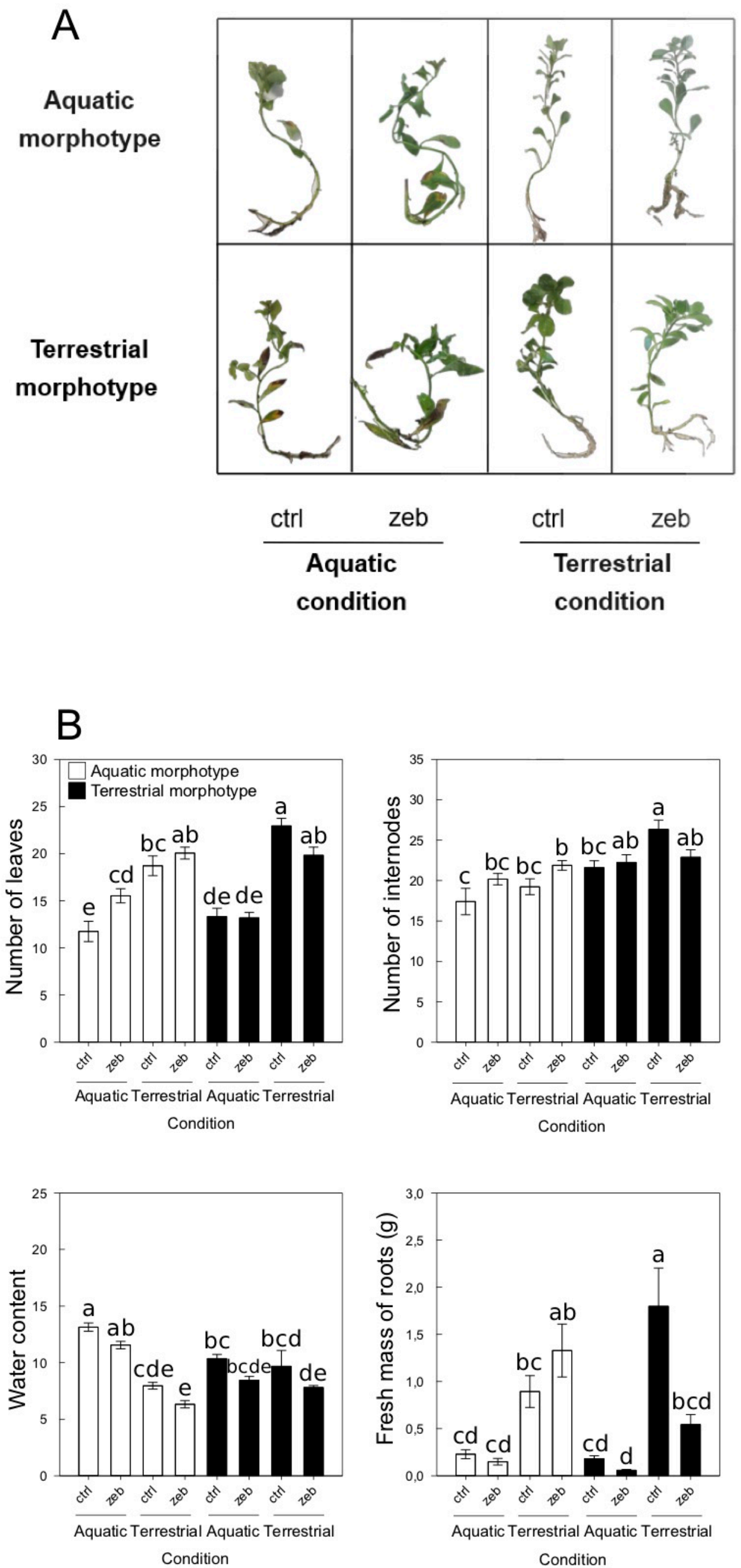

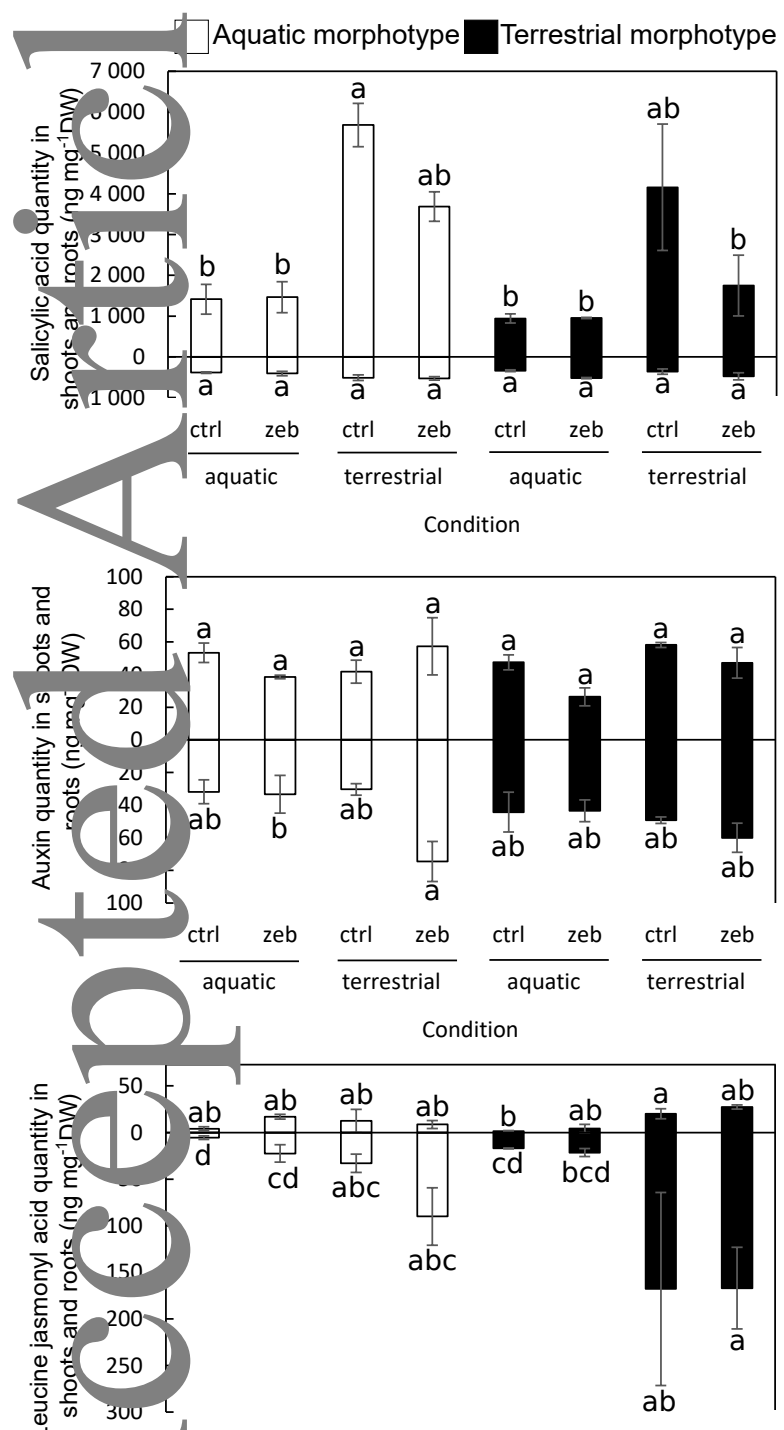

$\frac{c t r l \text { zeb }}{\text { aquatic }} \frac{\mathrm{ctrl} \text { zeb }}{\text { terrestrial }} \frac{\mathrm{ctrl} \text { zeb }}{\text { aquatic }} \frac{\mathrm{ctrl} \text { zeb }}{\text { terrestrial }}$ 

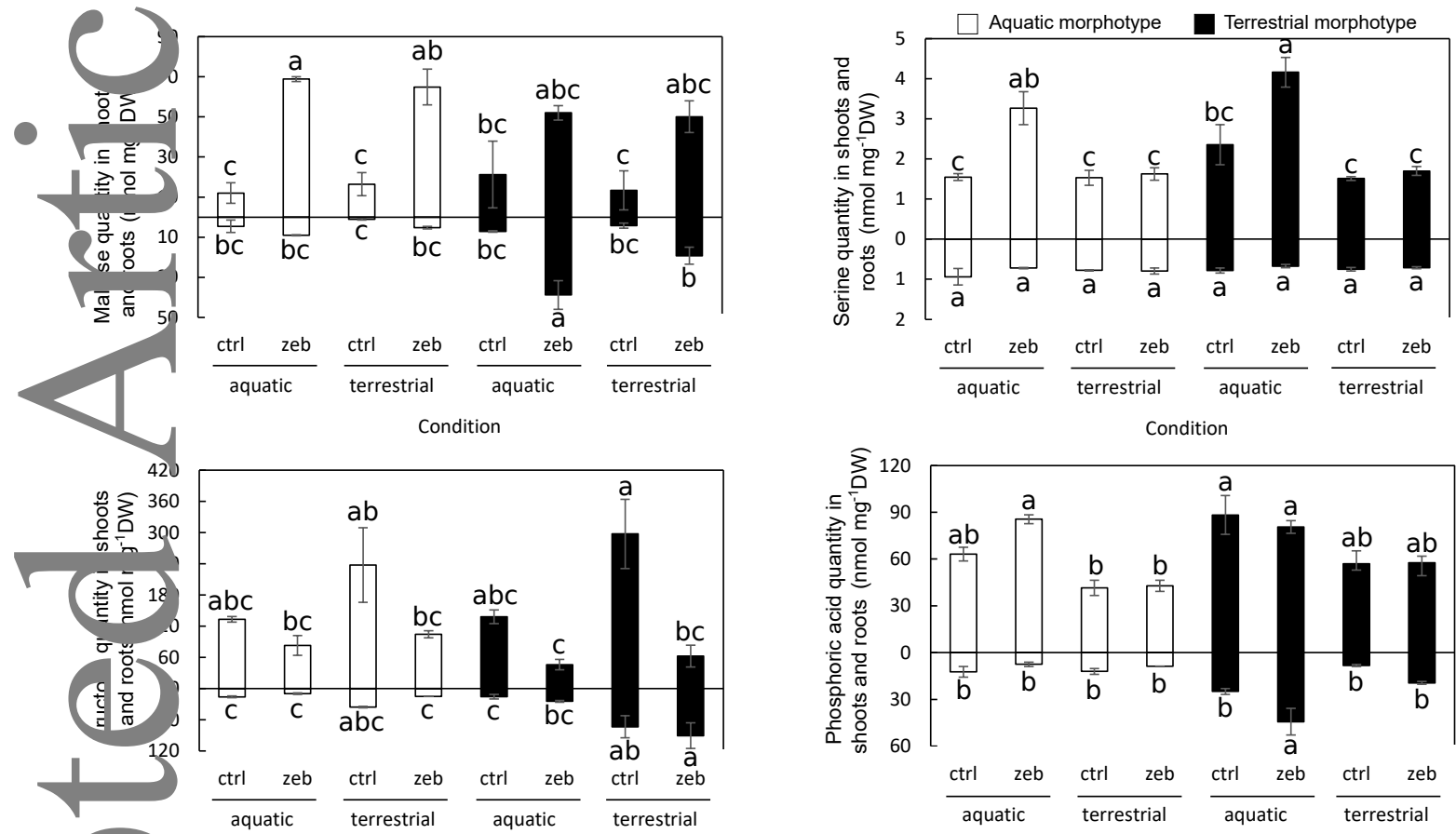

Condition
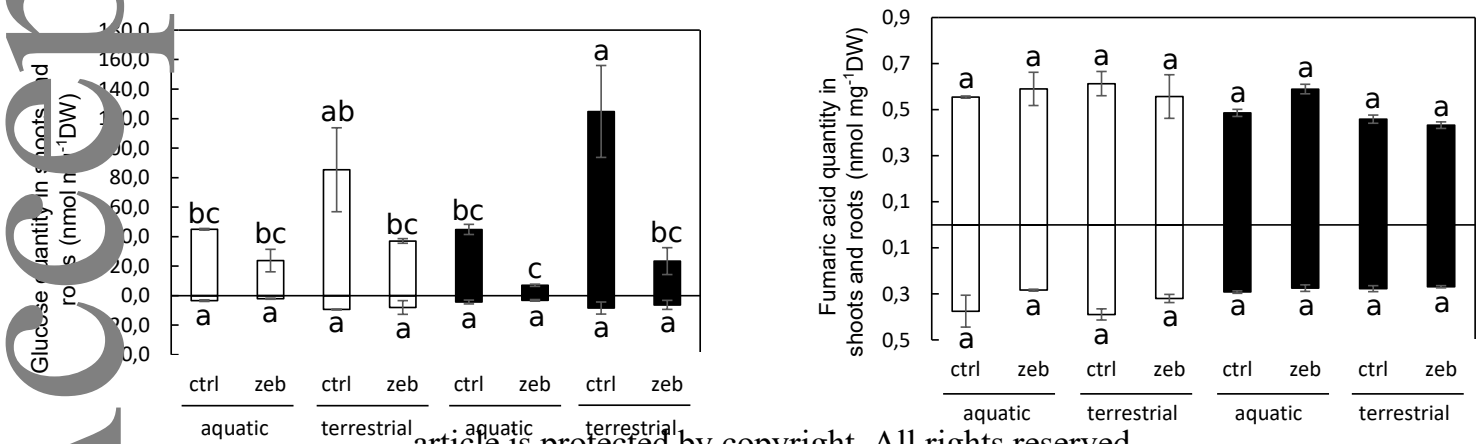

article is protected by copyright. All rights reserved. condition 

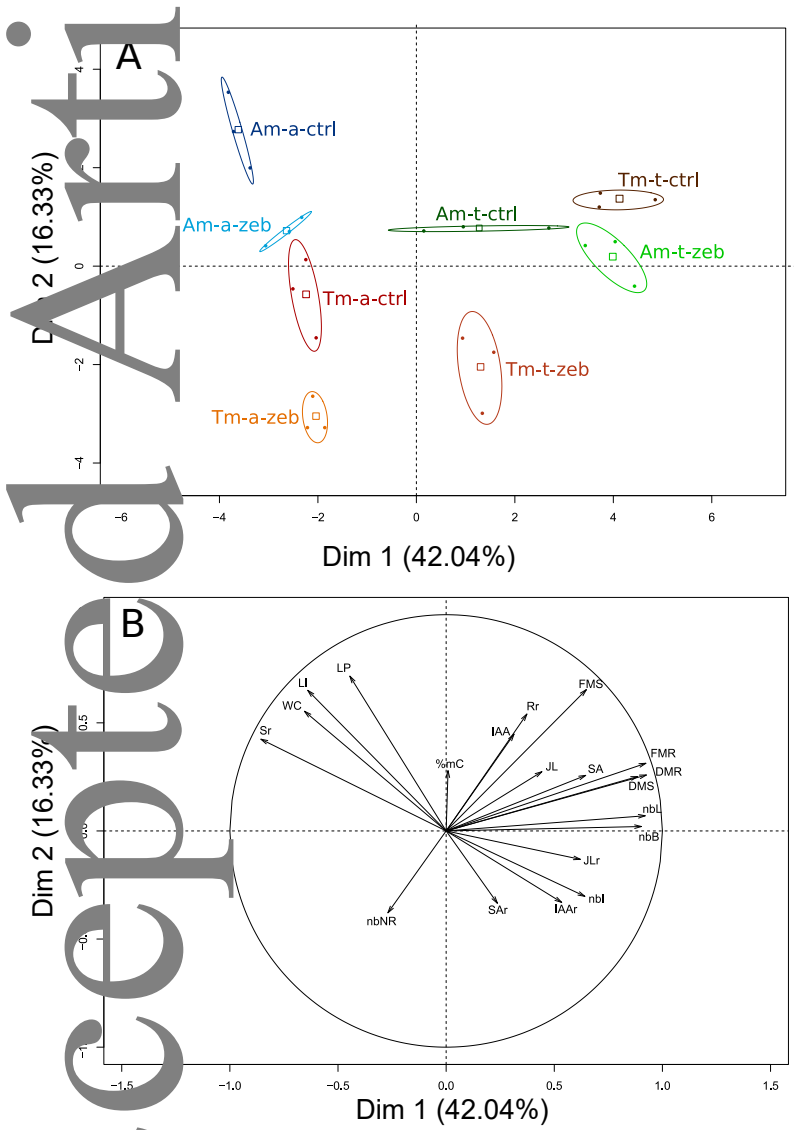